Journal of Teaching and Learning with Technology, Vol. 4, No. 1, June 2015, pp. 22-39. doi: 10.14434/jotlt.v4n1.12946

\title{
Using NetLogo as a Tool to Encourage Scientific Thinking Across Disciplines
}

\author{
David Gammack ${ }^{1}$
}

\begin{abstract}
Abstract: In this article we discuss the possible uses of NetLogo as an educational tool for High School and early-years undergraduate students. The paper is geared towards teachers from all disciplines who require students to problem solve, be quantitative and logical but want a project orientated platform to build or reinforce knowledge. The tools and methods herein were chosen specifically to be picked up by non-computer literate users. The goal is to highlight possible ways to excite students who perceive themselves to be weak mathematically through nontraditional computer-based exercises. In essence, we wish to encourage students to understand technology so they interact via easy coding rather than solely pushing buttons on an interface. Here we choose a model of toxoplasmosis gondii to demonstrate our ideas and show how scientific thinking and mathematical modeling can be used by the wider teaching community. Although these methods could be used for any age group or scholarly level, here we build our ideas around students who have seen high school algebra and may have studied one semester of differential calculus. Finally, we give some ideas of how NetLogo could be incorporated across the curriculum. Code for each module is available for download to assist teachers (Gammack, 2015).
\end{abstract}

Keywords: interdisciplinary teaching, scientific thinking, agent-based modeling, NetLogo

Computational technology is used in all walks of life, from the abundance of "smart" phones, appliances around the house, even the humble bicycle can have electronically operated gear shifters. For the majority of these, the technology is used purely via an interface - there is no deeper understanding or modifying of the underlying code. As the world becomes more interconnected, and jobs rely on connecting ideas from different disciplines, we want our graduates of the future to be comfortable with both using the interface and being able to appreciate the capabilities of the underlying technology. While not everyone needs to be hotshot coder, it can be helpful to understand some of the issues involved. For example, a project manager, whose deliverable is an oven monitor that switches the heat off when the moisture levels fall below a certain threshold, should have a broad understanding of the individual tasks of her team members. Similarly, researchers from all disciplines use computational technology to varying degrees: pure mathematicians may only use documentation preparation software (Word, LaTex, etc.), whereas a geography $\mathrm{PhD}$ student may need to code GIS (geographic information systems) mapping software. To help graduates understand the importance of a deeper understanding of technology, scientific thinking and hands-on building needs to be encouraged

\footnotetext{
${ }^{1}$ Honors Program Director, Associate Professor, Department of Mathematics, Marymount University, 2807 N. Glebe Road, Arlington, Virginia, 22201
} 


\section{Gammack, D.}

throughout education at various age-group levels. Although this is a challenging proposal, the authors hope to show that engaging students with realistic projects can aid both their comfort level with technology, and also develop their subject matter knowledge.

Working in a small liberal arts college with a tiny population of mathematics majors, the authors instead work with students who want to do research from non-mathematics disciplines (Biology and Business being the main culprits). Usually, these students have had high school mathematics (algebra/trigonometry/precalulus) and may have started a college level mathematics class (calculus or statistics). A complication is picking tools that students can use so that they can make progress and have a fulfilling experience despite their lack of computational skills. The same challenges are true in other disciplines and non-undergraduate students. In our experience, the NetLogo (Wilensky, 1999) (see §2) platform serves both purposes.

Consider the following example from political science. In a given population of voters, can we determine the boundaries for voting districts that will create safe seats for the incumbent candidate? The basis of this problem is easily understandable and applicable to many students. It is also a problem that can be modeled and experimented upon using Agent-Based Models $(\mathrm{ABM})$. A starting point for this project would be the voting model that can be accessed via the Models Library in NetLogo (Wilensky, 1999). A more academic look at using ABM to assess the outcome of an election between political parties can be found in Laver and Sergenti's book (Laver \& Sergenti, 2011). The ABM in the NetLogo library bases preference on neighboring voting patterns (peer pressure). An interesting extension would be to consider the environment as a State and use the ABM to decide voting boundaries so that the result of the next voting cycle is biased towards the incumbent party (gerrymandering). This example highlights how a "nonmath" problem can be used to hook students in and teach them modeling and reasoning skills.

Agent-Based Models (ABM) are computational descriptions of real world phenomena. The two main components to an ABM are the environment and its agents. The environment is the space in which phenomena occur: a street, a house, bodily tissue, or an abstract environment. Agents inhabit the environment: cars and people on a street, people, pets and germs in a house, cells and bacteria in tissue. To design an ABM the user needs to make assumptions about the interactions between individual agents and between the agents and their environment. These interactions could be logical (if $x$ then $y$ ), probabilistic (there is an $x \%$ chance of $y$ ) or functionbased $(y=f(x))$. Once the interactions have been coded, simulations can be run and conclusions drawn. For a full introduction on ABM, see (Railsback \& Grimm, 2012).

The model presented here was developed as part of a research assignment with two biology majors. However, the authors hope that it is apparent how this model (or a new teachermotivated model) can be developed by students from HS and up. To assist teachers using this material in the classroom, all code is available for download. Please note that code is like a modern house in a new community; there are similar structures found around a neighborhood, but no two houses are exactly alike even if it is only a difference in paint color. Be suspicious if your student's code is an exact match to the downloadable versions.

Although there are many different ABM platforms (including Mason, NetLogo, RePast, SWARM) (Nikolai \& Madey, 2009a), we use NetLogo for three reasons: (1) it is free; (2) it is simple to download and run on mac or pc; and (3) although not as rich as some of the other platforms, the syntax makes it easy for non-programmers to progress quickly. For a fuller

Journal of Teaching and Learning with Technology, Vol. 4, No. 1, June 2015. jotlt.indiana.edu 
Gammack, D.

introduction to ABMs and NetLogo, please see (Gammack, Schaefer, \& Ga, 2013;

Laubenbacher, Jarrah, Mortveit, \& Ravi, 2012).

NetLogo is an agent-based modeling tool that allows the user to specify how agents (people/cells/objects) interact with each other and their environment and to then examine how the system evolves over time. We have led student research projects using NetLogo to model a variety of natural phenomena (cholera outbreak, the development of neuronal pathways and toxoplasmosis spread) over the past 4 years and a few things have become clear: (1) nonmathematics/IT students are not afraid of NetLogo; (2) students are excited by the progress they can make in a short time; (3) it helps enforce precision of thought and develop scientific rigor. Additionally, NetLogo is a useful tool across the academic spectrum: from mathematics/IT undergraduates to students who have yet to take a college mathematics class. The goal of this paper is threefold: (1) to give a brief overview of NetLogo; (2) highlight ways in which mathematical and scientific ideas can be incorporated into the learning experience through modeling the spread of toxoplasmosis gondii on a pig farm; (3) demonstrate how NetLogo can be incorporated across disciplines and mathematical levels (High School through College).

For the purposes of this paper, we assume that students have taken (or are taking) high school algebra, but we also include Learning Experiences for more mathematically advanced students. In $\S 2$ we develop a NetLogo model and describe some parallel classroom exercises that can be picked up and used by anyone willing to open a new computer program; $\$ 3$ gives some ideas about using NetLogo across other disciplines. In $\S 4$, we present results from student NetLogo usage and we close with $\S 5$, a brief discussion on assessing the validity of NetLogo as an educational tool.

\section{Modeling and Learning with NetLogo}

Throughout this work, we highlight the learning opportunities of NetLogo via a studentinitiated project that models toxoplasmosis gondii on a pig farm. The tools used were intentionally chosen to welcome the widest audience. They are free, easy to use and well documented. Working examples of the custom code required are available for download to provide a guide and support. The models themselves were chosen to be relatively simplistic to allow students and teachers to focus on learning how to break a problem apart and model it. At each stage of modeling, we present a "learning experience" that can be used to develop and assess each student's progress.

\section{A Note about Student Driven Models}

One potentially difficult aspect of modeling natural phenomena is deciding what is crucial information and what can be neglected. This can be a problem for students as they sometimes have some trouble letting go of ideas. For example, when developing a model of the spread of a disease a student might rightly argue that an individual's age effects their immune system, which in turn plays a part in their likelihood of becoming infected. However, that aspect could be brought in later in the standard modeling "circle" (see Figure 1) when the user reassesses her assumptions and refines the model. For the purposes of this article, we consider a

Journal of Teaching and Learning with Technology, Vol. 4, No. 1, June 2015. jotlt.indiana.edu 
Gammack, D.

simple model of the spread of toxoplasmosis gondii. The original (more complicated!) model was developed by two undergraduate Biology students at Marymount University. We have mapped out the initial models so that it is easy for students to make initial steps towards their goals. As they progress, students should then be encouraged to refine and expand their models once the basics are grasped.

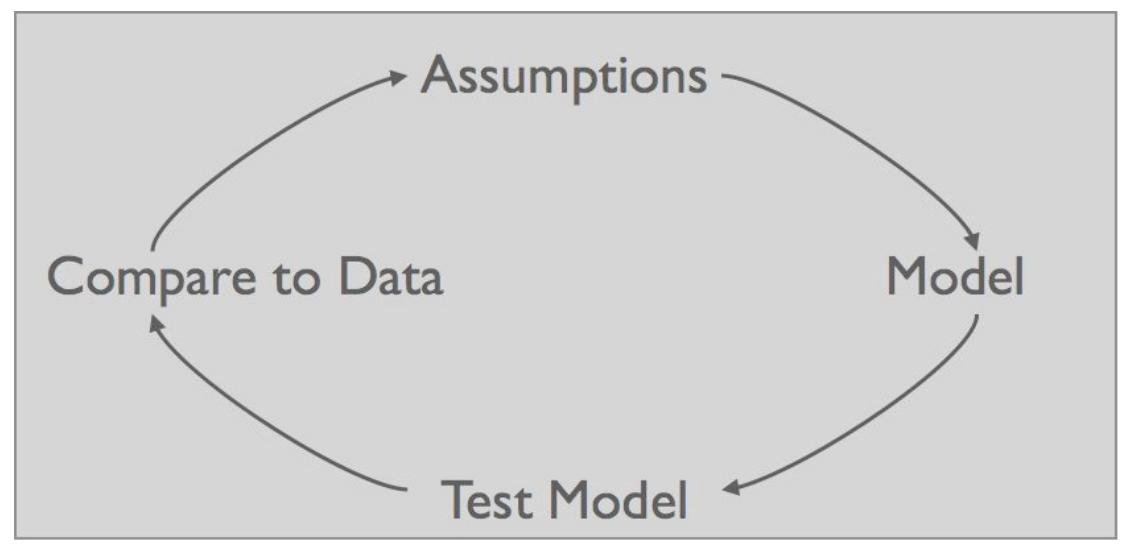

Figure 1: Model Development Cycle

\section{Basics of NetLogo}

When NetLogo is run, a blank GUI Interface appears with three main tabs at the top: Interface, Information, and Procedures (see Figure 2). The tabs purposes are as follows: Interface - where the simulations are run; Information - for comments on the model's assumptions and uses; Procedures - where the code is written. In addition, Settings can be used to define the overall size of the simulation window and the patch and font sizes. In the next three subsections we will introduce the basics of setting up the environment, the agents and their interactions.

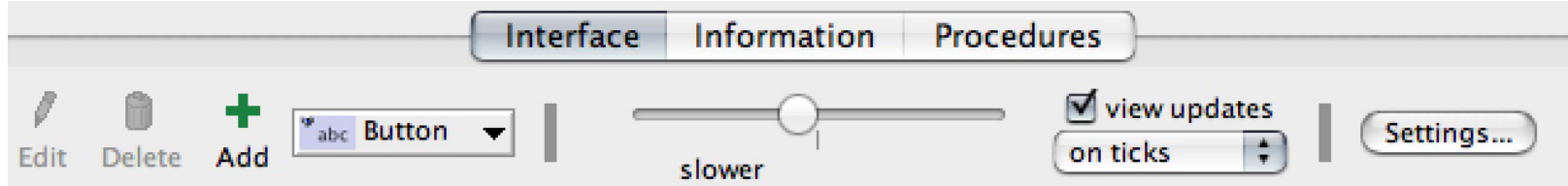

Figure 2: NetLogo Control Bar

The remainder of this paper concentrates of the building of the model (the Procedures part of NetLogo), but here, for completeness, we give a brief overview of the Interface. Figure 3 shows the NetLogo program when initially opened - note that Interface is highlighted, indicating

Journal of Teaching and Learning with Technology, Vol. 4, No. 1, June 2015. jotlt.indiana.edu 


\section{Gammack, D.}

that the user has arrived at the front-end (user interface). The user can add/alter three main components at this point:

- Add user interface controls. E.g. buttons that run all or part of the code; sliders that allow users to alter model parameters; on/off switches to allow for certain routines to be ignored or incorporated (for example, a user may be testing the hypothesis that quarantine is the only way to stop an outbreak of measles in a school). In addition, the user can define outputs to be displayed (plots, population numbers, etc.).

- Alter how the output is displayed. E.g. change the speed and/or have the simulation update the output every "tick" (the time interval being used).

- Alter environmental settings. E.g. change the dimensions of the environment, the size of each patch/agent.

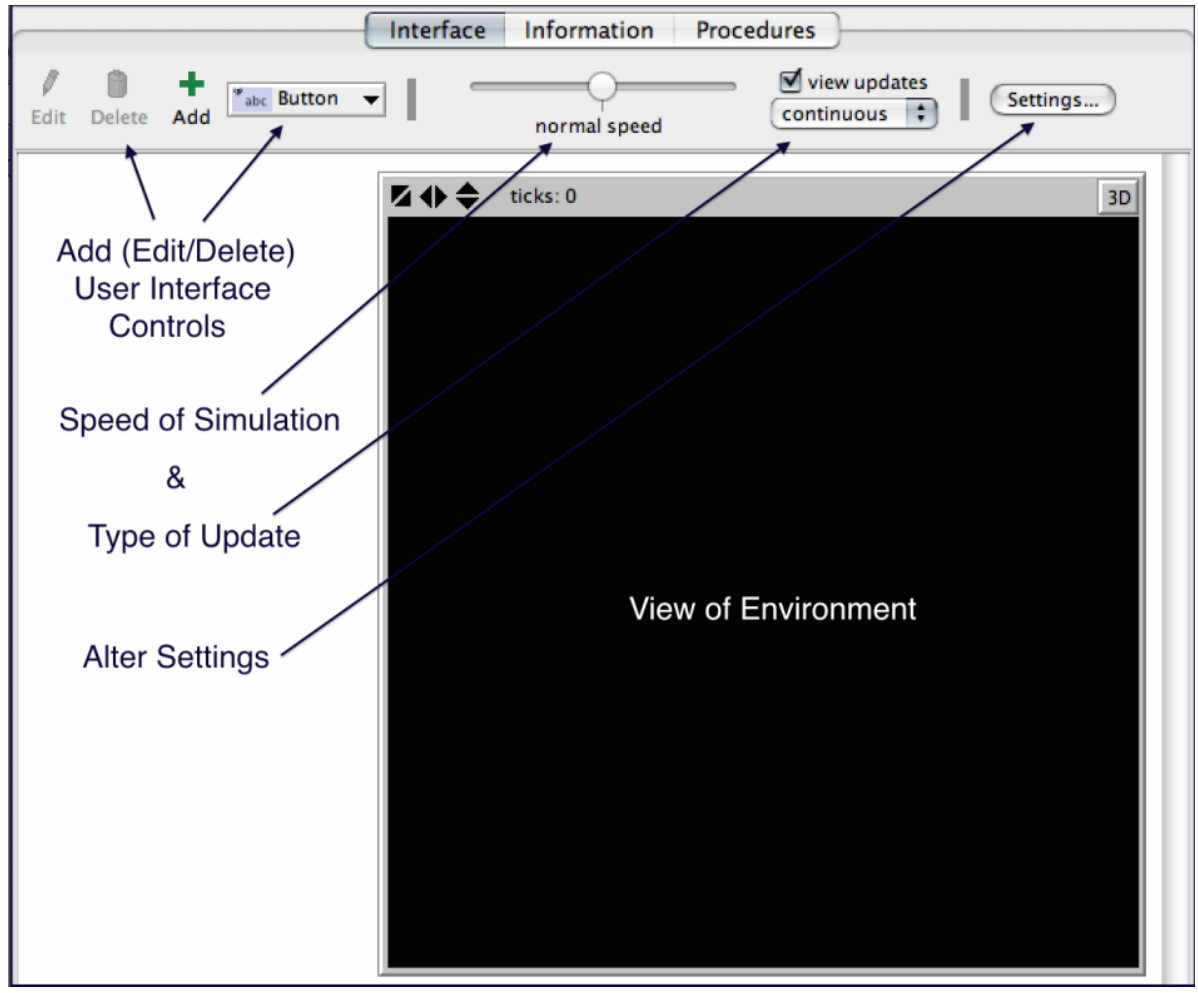

Figure 3: NetLogo Interface

Defining the Environment

Journal of Teaching and Learning with Technology, Vol. 4, No. 1, June 2015. jotlt.indiana.edu 
Gammack, D.

The NetLogo environment is made up of discrete areas that agents move around on called patches: imagine if roads and sidewalks were replaced with paving slabs rather than a continuous layer of concrete. Each patch can have its own properties: color, dirtiness, temperature, stickiness, etc. For simplicity, we assume the farm is square, with a rectangular pig enclosure. The farm covers the whole area of the screen and the pig enclosure takes up one section of it. We color the boundary of the farm yellow and the pig enclosure brown. The code required to build the basic layout is given below. (Note that lines beginning with;; are comments to the user.) The code can be found in NetLogo file enviro-1 (NetLogo Models, n.d.) and in Error! Reference source not found.

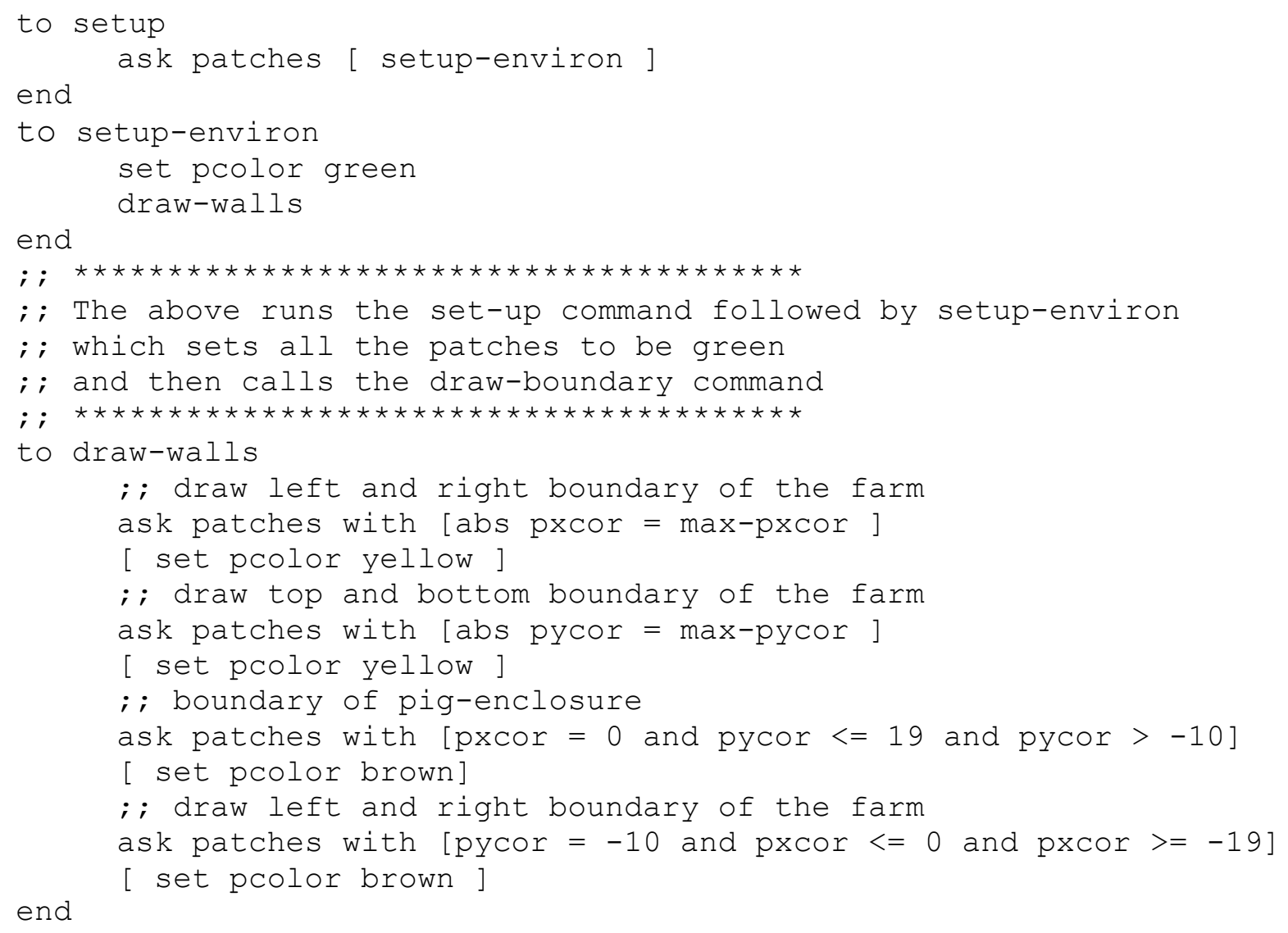

Figure 4: NetLogo code for Farm Layout

Note that under the settings tab in NetLogo the dimensions of the environment can be set and that, in this case, the origin is at the center and both axes have dimensions $(-20,20)$. Also note that all code is available via download.

Now, when we click to the Interface tab, a button needs to be defined that will implement the "set-up" code. First, we click on "button" and an edit window opens (Figure 5). Under

Journal of Teaching and Learning with Technology, Vol. 4, No. 1, June 2015. jotlt.indiana.edu 


\section{Gammack, D.}

"Commands" we write "setup" which is the name of the set up code (see above) and then choose a display name. Once we click "OK" there will be a button on the interface that allows us to execute that part of the code. All buttons are set up this way, and we leave it to the reader to examine the individual codes to see how other interface controls are defined. Figure 6 shows the output after the "Setup" Button has been pressed.

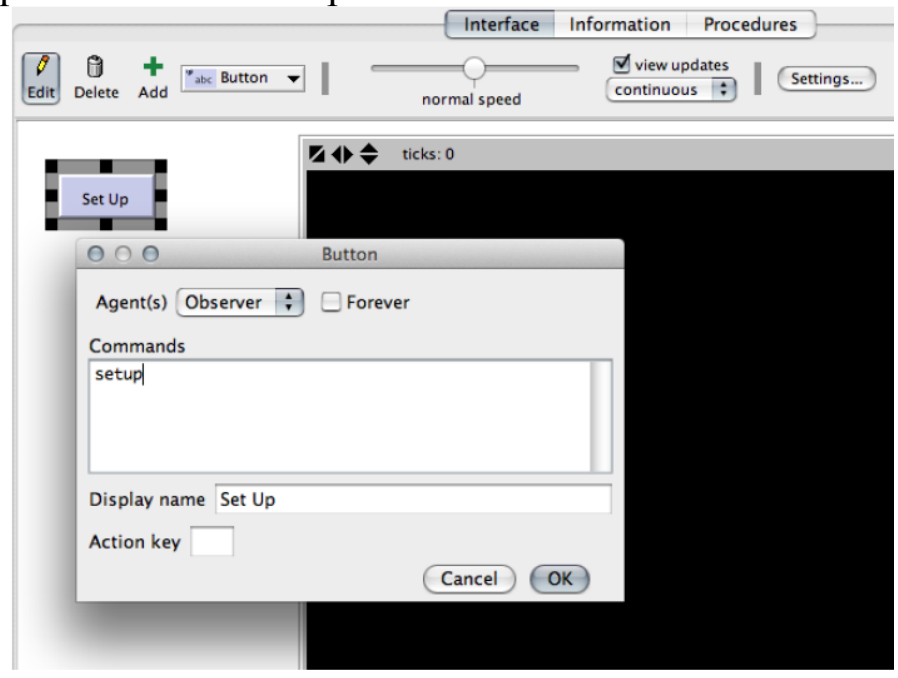

Figure 5: Creating a Setup Button

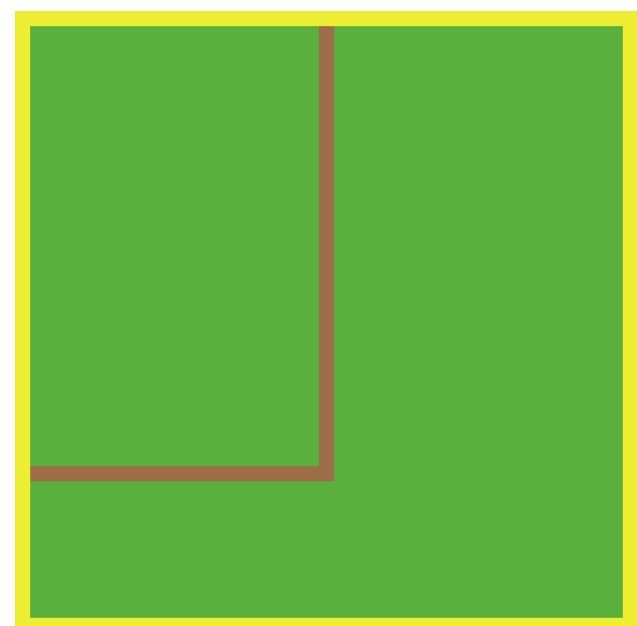

Figure 6: Farm Environment. Yellow indicates the border of the farm, brown indicates

the pig enclosure and green is the environment on which the pigs move (grass/field).

\section{Learning Experience}

Journal of Teaching and Learning with Technology, Vol. 4, No. 1, June 2015. jotlt.indiana.edu 
Gammack, D.

Although this can be thought of as purely an opportunity to develop some low-level coding skills, exercises could be brought in to engage students in relevant mathematical ideas. Ideas for questions:

Example 2.1

(a) (Algebra) If the pig enclosure needs $100 \$ m^{\wedge} 2 \$$ of open land on the south (bottom) side and each pig sty is $2 \$ m \$ \$$ times $\$ 4 \$ m \$$ how many sties could fit end-to-end in the enclosure?

(b) (Algebra) If each sty requires 1 m of open ground around it (on all sides), how many sties could fit in the enclosure?

(c) (Algebra) If each sty holds 8 pigs, how many pigs can the farmer have?

(d) (Calculus) The farmer has $38 m$ of fencing. What is the maximum area she can enclose for the pigs?

(e) (Biology/Ecology) What are the guidelines regarding healthy dimensions of pig sties? How many pigs should be allowed in each sty?

(f) (Business/Algebra) The initial cost of setting up the farm is $1 \$ 9,500$ and the cost of rearing a pig is $1 \$ 400$ per pig. If the farmer can sell a pig for $1 \$ 450$, how many pigs must she rear (and sell) before making profit?

Defining Agents

Agents populate the NetLogo environment. Just like the environment, agents can have specific properties (color, age, level sickness, dirtiness, etc.). Additionally, agents can move about the environment, but we leave that till $\$ 2.5$. Here we introduce pigs into the farm. First we need to define a breed called pigs, then create some pigs, and give them a shape and a place to start. The code for implementing this is as follows in Figure 7 (NetLogo file enviro-2). Note that the following code (and that of the remainder of the paper) is additions and modifications to the original "set-up" code introduced in $\$ 2.3$.

Journal of Teaching and Learning with Technology, Vol. 4, No. 1, June 2015. jotlt.indiana.edu 
Gammack, D.

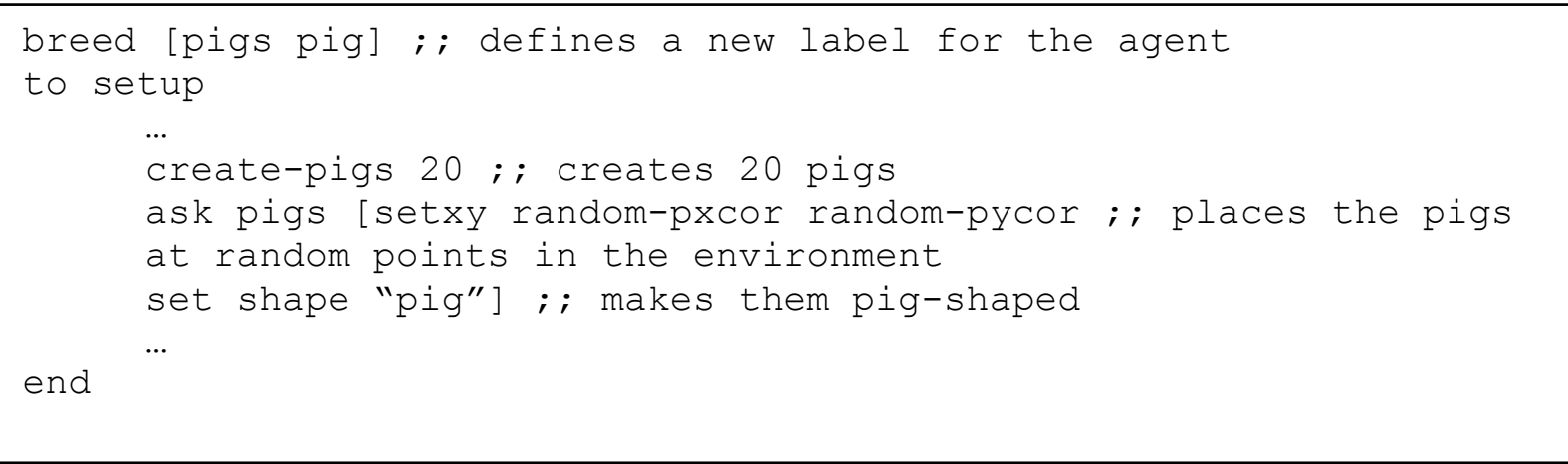

Figure 7: NetLogo code to define Pigs.

Here, ask pigs [...] means that all commands given between the brackets are applied to each pig. In this case, each pig is pig-shaped and is sent to a random (integer valued) $(x, y)$ coordinate. Note that information on a command can be found by right clicking on the word in the procedures tab and selecting "Quick Help" or searching the help documents.

\section{Learning Experience}

At this point, when students run the model they will (hopefully) see two problems: (1) pigs are everywhere - in the enclosure, the rest of the farm, even on the boundaries of the environment, and (2) the pigs are all different colors. This leads to a simple coding exercise:

\section{Example 2.2 Coding}

(a) Make all the pigs pink. Hint: what does the command color do?

(b) Make the placement of pigs be random within the pig-enclosure. Hint: this is trickier than it initially seems. First define an area called pig-enclosure and then use the command move-to one-of pig-enclosure when setting up the pig population.

Now we need to work out how the agents interact with their environment and each other.

\section{Defining Interactions}

In NetLogo, we need to define how the environment (individual patches) is affected by an agent as it passes through it, and vice-versa. There are various, standard, considerations (ex. movement of agents) but rather than pick and choose random concepts, we discuss the development of a model of toxoplasmosis gondii spread as the motivation for developing certain interactions. This is also a great method of learning as students can decide what is necessary to include.

Journal of Teaching and Learning with Technology, Vol. 4, No. 1, June 2015. jotlt.indiana.edu 
Gammack, D.

\section{Toxoplasmosis Background}

Toxoplasma gondii can infect any warm blooded animal, but only breed in cats (Dubey \& Frenkel, 1998; Flegr \& Havlicek, 1999; Fuller Torrey \& Yolken, 2003; Miro, Montoya, Fisher, \& Fuentes, 2008; Tenter, Heckeroth, \& Weiss, 2000). T. gondii can alter the behavior of humans, causing them to exhibit some of the following symptoms: an increased affinity for cats, headaches, fevers, and confusion. Although, toxoplasmosis is a not a deadly disease, it is detrimental to people with autoimmune deficiencies (Jiang, Sullivan, Su, \& Zhao, 2012). Research has shown that infected drivers have a six-times greater risk of traffic accidents (Flegr, Klose, Novotna, \& Berenreitterova, 2009). It has also been linked to schizophrenia (Fuller Torrey $\&$ Yolken, 2003). Internationally, some countries have a 95\% infected rate, with hot and humid regions having the highest prevalence (Toxoplasmosis, 2013). Studies have shown a rising rate of toxoplasmosis infection in farm settings. In particular, researchers have shown several cases of toxoplasmosis in pig farms in China and Brazil (Du et al., 2012; Piassa et al., 2010). Additionally Weigel et al. have highlighted risks of infection on farms in Illinois (Weigel, Dubey, Dyer, \& Siegel, 1999).

Unlike the model of Jiang et al. (Jiang et al., 2012), here we consider purely the interaction between the infectious adult cats and the pigs on the farm. In this case, the pigs are not actively spreading the disease around the farm, but could contribute in infecting humans via the environment and by infecting the food chain (Kijlstra et al., 2004; Tenter et al., 2000; Weigel et al., 1999). Table 1 lists some very basic assumptions we take from the literature. The NetLogo files enviro-3 and enviro-4 have all the relevant code for the rest of the learning experiences up to Ex. 2.6.

Table 1: Basic cat and pig population assumptions

\begin{tabular}{|l|l|l|}
\hline & Cat & Pig \\
\hline Movement & Random throughout the farm & Random within pig enclosure \\
\hline Disease & $\begin{array}{l}\text { Spread by feces } \\
\text { Constant levels within host }\end{array}$ & Infected by feces \\
\hline Reproduction & Neglected & Neglected \\
\hline
\end{tabular}

Learning Experience

Example 2.3 Coding

(a) Define a new breed: cats.

(b) Place 5 cats randomly on the farm.

(c) Make all the cats black.

Journal of Teaching and Learning with Technology, Vol. 4, No. 1, June 2015. jotlt.indiana.edu 
Gammack, D.

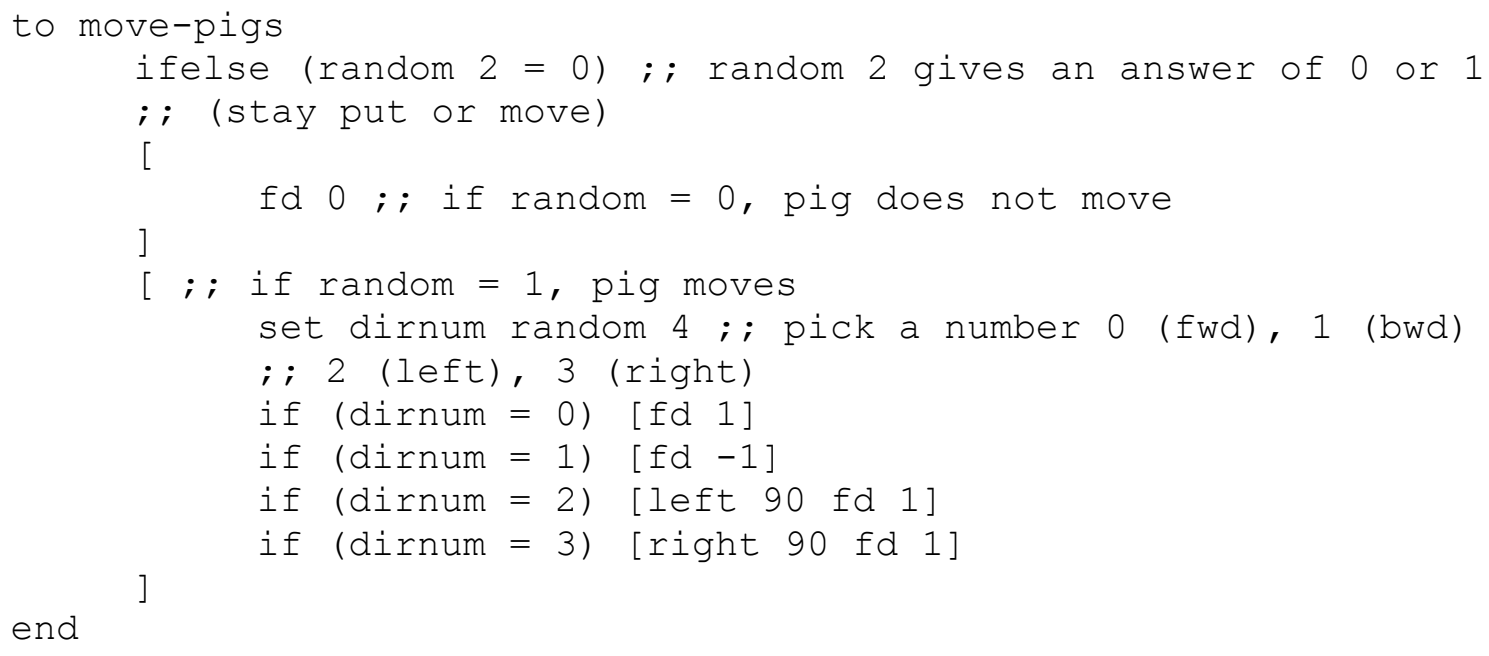

Example 2.4 Modeling (do not try to code these yet)

(a) (Probability) If the animals are moving randomly, how can we think about this in terms of probabilities? What are the chances of an animal moving left/right?

(b) (Biology) How can we decide when the cats will leave feces on the ground?

(c) (Biology/Modeling) What are we neglecting that we should not leave out?

For pig movement we could assume that they have an equal probability of moving or staying put. If they move, the probability of each direction is the same. Therefore, the code could be:

However, pigs should not be able to run through walls!

\section{Learning Experience}

Example 2.5

(a) (Probability) What is the probability of moving left?

(b) (Coding) How can you stop the pigs leaving the pig enclosure? Hint: one method is for the pigs to check the color of the patch they are going to move onto and if it is the color of a wall/boundary, do not let the pig move there.

(c) (Modeling) What is the model missing?

Figure 8: NetLogo code to move pigs

Journal of Teaching and Learning with Technology, Vol. 4, No. 1, June 2015. jotlt.indiana.edu 
Gammack, D.

With the cat population, we need to incorporate movement and defecation during the simulation. For this (and for the pig movement) timing is important. Therefore, we need to develop a way of keeping time within the simulation. First, there is a command $t i c k$ which does exactly what it sounds like it should: it moves the simulation one "tick" (or one time unit). The following piece of code demonstrates the use of tick. The code in Figure 9 will now keep running ad infinitum. This raises a couple of questions: (1) how do we define a unit of time; and

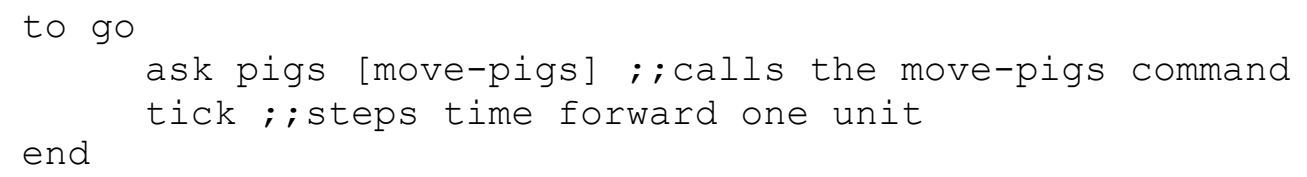

(2) how do we end a simulation. Both of these are relatively straightforward exercises:

Learning Experience: Modeling/Mathematics/Coding

Example 2.6

(a) Define mins/hours/days as global variables assuming that each tick represents 1

Figure 9: NetLogo code to move pigs in time

minute. Hint: in setup initialize mins/hours/days to zero and then after the ti ck update each variable. Note that to update hours and days you will need the mod command.

(b) Make the simulation end after 60 days. Hint: you will need the stop command.

(c) Stereotypically, cats are active, pigs are lazy! Can you make the cats move more often than pigs? (Hint: pigs do not have to move every tick.)

At this point, students can build in the more complex parts of the natural phenomena: the spread of the infection. To start with, it is easier to get students to assume that cats defecate at set times of day and that they leave behind a set amount of toxoplasmosis. Then, when a pig moves onto an infected patch, make the pigs chance of infection be 50/50.

\section{Learning Experience: Modeling/Coding}

Example 2.7

(a) Assume that cats defecate 4 times a day (every 6 hours), and when they do, they infect whichever patch they are currently standing on. Make an infected patch turn red. Hint:

Journal of Teaching and Learning with Technology, Vol. 4, No. 1, June 2015. jotlt.indiana.edu 
Gammack, D.

create an infection? variable that the patches own that becomes true when a cat defecates on it.

(b) Make the pigs check the infection status of the patch they are on and then have a 50/50 chance of becoming infected. Make an infected pig turn black.

At this point students will have a very basic model of a pig farm that is host to a pack of feral cats infected with toxoplasmosis. The next stage of development would be to make the model more realistic and to include various disease specific events/variables. Suggestions for extensions would be:

Learning Experience: Modeling/Coding

Example 2.8

(a) Most diseases have a limited amount of time that they are viable outside of the host (equivalently, bacteria in feces becomes less infectious over time). What is this time for toxoplasmosis gondii and how could you incorporate this in the current model?

(b) Not all cats defecate at the same time! How can you randomize this process?

(c) At the moment pigs have a 50/50 chance of becoming infected? Research the infection rate for toxoplasmosis gondii and incorporate a more realistic probability of infection.

\section{Incorporation into the Classroom}

There are many ways to extend the model, either towards teacher-prompted scenarios, or by letting students have free-reign. What can be useful is assigning each small group a coding "guru" who has the responsibility to have all the code commented (annotated) so that it is easy to follow, and then try to combine the best parts of the individual projects into one deliverable from the class. For example, group one (G1) could be assigned to model the environment, G2 the movement of the animals, G3 the act of defecation spread of the disease, G4 the infectious state of the host, etc. Then, as groups deliver their sections, the next task would be to combine elements (combining G1 with G2 and G3 with G4 before pulling it all together). This takes planning, but students are excited to see how their individual elements can affect the overall outcome of the simulations.

Once the basic model has been constructed, questions can be posed like "How can you eradicate the disease on the farm?", "Would culling or quarantine be preferable?"

\section{Other Examples}

We have given a brief overview of the development of a NetLogo model of toxoplasmosis gondii and ideas on how to engage biology students in a small research project. It

Journal of Teaching and Learning with Technology, Vol. 4, No. 1, June 2015. jotlt.indiana.edu 
Gammack, D.

should be reasonably straightforward to see how other models could be developed to excite students. How about discussing a simple cold spreading through your HS? Students can work out that there are those students who are not sick/sick/have been sick and you can work out how their interactions effect the health of the school body as a whole. Then there is the spatial effects: what happens if just one person is sick and they are quarantined? Would that stop everyone else getting sick? Then the model can be developed by the students: some can develop the geometry of the school and how that geometry and the school's timetable alters how people interact. Other students can look at how to model the passing of germs between sick students and the environment/other students.

One of the neat things about NetLogo is that it can be a useful tool across the curriculum and there are many examples, from different disciplines, in the user-generated library to be examined. For example, if you are teaching an ethics or modern history course you could introduce Schelling's Tipping Model (Schelling, 1971) which investigates the effects of behavioral choices of individuals on a community. In brief, Schelling's Tipping Model can be seen as the effects of bias on a community: the model assumes that there are two agents (let's say red and green) and an agent has a percentage bias for living in a community where a certain number of its neighbors are of the same color. Now randomly assign each agent to a specific "home", and then let them move if they are "unhappy" (not enough red/green neighbors). The amazing thing is that segregation occurs at relatively low levels of bias: all agents could be happy with $50 \%$ of their neighbors being the other color and still there would be segregation. Students, to start with, could investigate this model on a chess-board and then, when they realize how large the community needs to be, investigate further via the simulation in the NetLogo library.

For a sociology project, how about studying the spread of knowledge in an environment: is it more likely that opinions/beliefs are passed peer-to-peer, or from teacher-to-student? Students can set up an environment where one person wants to be class president and that person can either campaign on issues, or could start a smear campaign. Which method works? A political science project could examine gerrymandering, as discussed in $\S 1$, or even look at how/if targeted advertising campaigns could influence an election. For a history project, students could develop a model of warfare. For example, there have been models of the Iwo Jima conflict based on Lanchester's warfare models (Lanchester, 1916; Engel, 1954). Most of the models do not contain spatial elements, so students could build the environment and then mimic the battle.

\section{Brief Summary of Student Experiences}

The authors surveyed six of eight undergraduate summer-research students who used NetLogo. Of those surveyed, 1 is a current Marymount University graduate student, the other 5 are alumni. A brief review of responses can be seen in Table 2 and Table 3.

Table 2: Basic Information about Students

\begin{tabular}{|l|l|l|l|l|}
\hline School Year & Degree Major & Subject Area of & Previous & Use of NetLogo \\
\hline
\end{tabular}

Journal of Teaching and Learning with Technology, Vol. 4, No. 1, June 2015. jotlt.indiana.edu 
Gammack, D.

\begin{tabular}{|l|l|l|l|l|}
\hline when initiating & & Project & experience in & increased \\
subject & & & subject area \\
Sophomore (4) & Biology (4) & Axon Guidance (2) & None (6) & Yes (6) \\
Junior (1) & Mathematics & Cholera (3) & & A Lot (4) \\
\hline Senior (1) & $(2)$ & Toxoplasmosis (1) & & \\
\hline
\end{tabular}

Table 3: Student's Use of Technology

\begin{tabular}{|l|l|l|l|l|}
\hline Coding & ABM/ NetLogo & Nervous about & Was NetLogo & Happy to use \\
Experience & Experience & using & difficult & technology in \\
technology & the future \\
\hline Limited (4) & None (6) & Yes (4) & No (5) & Yes (5) \\
& & No (2) & A little (1) & No (1) \\
\hline
\end{tabular}

Although our data points are limited to six (out of eight) students who responded to our survey, we claim that students found an increase in the subject knowledge, that they felt that NetLogo to be relatively easy to pick up, and that they would be happy to use technology in the future. However, it is important to ask if it is useful to use ABM, or other computer software, as a tool for learning. The authors would argue that it depends on why and how the platforms are used. For instance, the author and collaborators for the student projects had two main goals:

- to foster academic research in undergraduate students

- encourage scientific thinking

Both of the above aims were to be accomplished with students who were not necessarily interested or invested in learning about computational techniques, but who had been motivated by the idea of cross-discipline collaboration. For the purpose of this paper, the authors are

Journal of Teaching and Learning with Technology, Vol. 4, No. 1, June 2015. jotlt.indiana.edu 


\section{Gammack, D.}

highlighting the ways to encourage students to use technology in a deeper way than usual (active coding rather than relying on an interface).

However, we do want students to feel that the methods we use in teaching are useful in the classroom and beyond. For example, in (Gammack et al.,2013) a model for axon guidance is discussed. The initial development of the model was done by two biology majors (one who had yet to take calculus I). The project was intended to be a laboratory-based investigation of axon response to different guidance cues. The students realized that, due to monetary and laboratory constraints, it would be impossible to make any tangible progress with the project in the time allowed. However, with a student did note that "... for this particular project the lab work, if it had been done more extensively, would have been sufficient (sic)". A student who worked on the toxoplasmosis project noted that they could not have researched in the lab "... as the purpose of the project was to model the transmission of the disease. ... it would have been much more complicated and dangerous to test in lab (disease agent)".

\section{Discussion}

Agent-based modeling (ABM) can be an effective tool in a class setting when a project and outcomes are clearly defined, and the roles of individual groups are laid out. There are many software platforms that could be used. NetLogo has been highlighted here because of its ease of use, for non-computer programming literate students, and it is a free, cross platform package that has many user defined models loaded into its library.

Once students become confident playing with an ABM package it can become a useful tool for interdisciplinary study and can motivate students to look beyond the confines of their favored subjects. As previously stated, there are many different ABM platforms and each has their own strengths. For a full discussion, the authors suggest reading the excellent reviews by Nikolai and Madey (Nikolai \& Madey, 2009b) and Railsback et al. (Railsback, Lytinen, \& Jackson, 2006).

In terms of working with the software, students stated that NetLogo “...is easy to use and understand, the example scripts were extremely helpful in developing our own code. Also it was a great help to be able to just run the script and see the changes instantly to the Display (sic)". "Example scripts" in this instance refer to the library in NetLogo that has examples from art, mathematics, natural science, social science and more. All of the programs are ready to be run and, in the author's experience, students enjoy the "hacking" mentality they can employ as they start to build their own models. Another student noted that "I have gained key coding skills and it has added to my experiences. After graduating, noting that I am able to use NetLogo on my resume has helped me a lot in finding professional experiences." This is one of the author's goals: to enthuse non-IT undergraduates about the opportunities they can have by using crossdisciplinary tools.

Although we do not have enough data to statistically demonstrate the power of using $\mathrm{ABM}$ in the classroom, we hope that we have expressed the potential in using computational software across disciplines. The next generation of graduates need to be able to do more than just

Journal of Teaching and Learning with Technology, Vol. 4, No. 1, June 2015. jotlt.indiana.edu 
Gammack, D.

use the basic programs, they need to be able to see the potential problem solving capabilities at their fingertips and help implement those solutions.

\section{Acknowledgements}

The authors thank undergraduate students Lalla Maiga and Cyndi Trang for their initial work on the toxoplasmosis project.

\section{References}

Du, F., Zhang, Q., Yu, Q., Hu, M., Zhou, Y., \& Zhao, J. (2012). Soil contamination of toxoplasma gondii oocysts in pig farms in central china. Vet. Parasitol., 187, 53-56.

Dubey, J. P., \& Frenkel, J. K. (1998, May). Toxoplasmosis of rats: a review, with considerations of their value as an animal model and their possible role in epidemiology. Veterinary

Parasitology, 77 (1), 1-32.

Engel, J. (1954). A verification of Lanchester's law. J. Op. Res. Soc. Am.,2 (2), 163-171. Flegr, J., \& Havlicek, J. (1999). Changes in the personality profile of young women with latent toxoplasmosis. Folia parasitologica, 46 (4), 22-28.

Flegr, J., Klose, J., Novotna, M., \& Berenreitterova, J., M. Havlicek. (2009). Increased incidence of traffic accidents in toxoplasma-infected military drivers and protective effect rhd molecule revealed by a large-scale prospective cohort study. BMC Inf. Dis., 9 (1).

Fuller Torrey, E., \& Yolken, R. H. (2003, November). Toxoplasma gondii and schizophrenia. Emerg. Infect. Dis., 9 (11), 1375-1380.

Gammack, D., (2015) NetLogo Models, https://sites.google.com/a/marymount.edu/netlogomodels/models/toxoplasmosis, Department of Mathematics, Marymount University, Arlington, VA.

Gammack, D., Schaefer, E., \& Gaff, H. (2013). Global dynamics emerging from local interactions: Agent-based modeling for the life sciences. In R. Robeva \& T. Hodge (Eds.), Mathematical concepts and methods in modern biology. Elsevier.

Jiang, W., Sullivan, A., Su, C., \& Zhao, X. (2012). An agent-based model for the transmission dynamics of toxoplasma gondii. J. Theor. Biol., 293 , 15-26.

Kijlstra, A., Eissen, O. A., Cornelissen, J., Munniksma, K., Eijck, I., \& Kortbeek, T. (2004). Toxoplasma gondii infection in animal-friendly pig production systems. Invest Ophthalmol Vis Sci., 45 (9), 3165-3169.

Journal of Teaching and Learning with Technology, Vol. 4, No. 1, June 2015. jotlt.indiana.edu 
Gammack, D.

Lanchester, F. (1916). Aircraft in warfare: the dawn of the first arm. London: Constable. key chapters reprinted as: Mathematics in warfare. The world of mathematics, j. Newman (ed.) 1956. New York: Simon and Schuster.

Laubenbacher, R., Jarrah, A., Mortveit, H., \& Ravi, S. (2012). Agent based modeling, mathematical formalism for. In R. Meyers (Ed.), Computational complexity (pp. 88-104). Springer.

Laver, M., \& Sergenti, E. (2011). Party competition: An agent-based model. Princeton University Press.

Miro, G., Montoya, A., Fisher, M., \& Fuentes, I. (2008). Toxoplasmosis - an update. EJCAP, 18 (3), 246-254.

Nikolai, C., \& Madey, G. (2009a). Tools of the trade: a survey of various agent based modeling platforms. J. Art. Soc. Soc. Sim., 12.

Nikolai, C., \& Madey, G. (2009b). Tools of the trade: A survey of various agent based modeling platforms. Journal of Artificial Societies and Social Simulation, 12 (2), 2.

Piassa, F., de Araujo, J., da Rosa, R., Mattei, R., da Silva, R., Langoni, H., \& da Silva, A. (2010). Prevalence and risk factors for toxoplasma gondii infection in certified and non-certified pig breeding farms in the Toledo microregion, pr, brazil. Rev. Bras. Parasitol. Vet., Jaboticabal,19, $152-156$.

Railsback, S. F., \& Grimm, V. (2012). Agent-based and individual-based modeling: A practical introduction. Princeton: Princeton University Press.

Railsback, S. F., Lytinen, S. L., \& Jackson, S. K. (2006). Agent-based simulation platforms: Review and development recommendations. Simulation, 82, 609-623.

Schelling, T. (1971). Dynamic models of segregation. J. Math. Soc., 1 ,143-186.

Tenter, A. M., Heckeroth, A. R., \& Weiss, L. M. (2000, November). Toxoplasma gondii: from animals to humans. International Journal for Parasitology, 30 (12-13), 1217-1258.

Toxoplasmosis. (2013). Retrieved from hppt://www.cdc.gov/parasite/toxoplasmosis/

Weigel, R., Dubey, J., Dyer, D., \& Siegel, A. (1999). Risk factors for infection with toxoplasma gondii for residents and workers on swine farms in Illinois. Am. J. Trop. Med. Hyg., 60 (5), 793798.

Journal of Teaching and Learning with Technology, Vol. 4, No. 1, June 2015. jotlt.indiana.edu 


\section{Gammack, D.}

Wilensky, U. (1999). Netlogo. http://ccl.northwestern.edu/netlogo, Center for Connected Learning and Computer-Based Modeling, Northwestern University, Evanston, IL.

Journal of Teaching and Learning with Technology, Vol. 4, No. 1, June 2015. jotlt.indiana.edu 